\title{
Commentary: Predicting adverse prognosis in chronic type B dissection: Are we there yet?
}

\author{
John A. Elefteriades, MD, PhD (hon), and Bulat A. Ziganshin, MD, PhD
}

\author{
From the Aortic Institute at Yale-New Haven Hospital, Yale University School of Medicine, New Haven, Conn \\ Disclosures: Dr Elefteriades is cofounder of CoolSpine, is a consultant for CryoLife, serves on the Data/Safety \\ Monitoring Board for Terumo, and serves on the Data/Safety Monitoring Board for Jarvik Heart. Dr Ziganshin \\ has nothing to disclose with regard to commercial support. \\ Received for publication July 18, 2019; accepted for publication July 22, 2019; available ahead of print Sept 26, \\ 2019. \\ Address for correspondence: John A. Elefteriades, MD, PhD (hon), Aortic Institute at Yale-New Haven Hospital, \\ Yale University School of Medicine, 789 Howard Ave, Clinic Building CB 317, New Haven, CT 06519 \\ (E-mail: john.elefteriades@yale.edu). \\ J Thorac Cardiovasc Surg 2020;159:2185-6 \\ $0022-5223 / \$ 36.00$ \\ Copyright (C) 2019 by The American Association for Thoracic Surgery \\ https://doi.org/10.1016/j.jtcvs.2019.07.068
}

Matsushita and colleagues ${ }^{1}$ are to be congratulated for their elegant and sophisticated statistical analysis in this issue of the Journal of the potential predictors of late poor outcome after type B aortic dissection. They have focused attention appropriately on the true uncertainty as to whether endovascular stenting should be performed routinely in the early stages of uncomplicated type B aortic dissection, rather than the standard "complication-specific approach" of medical management with anti-impulse therapy (in which surgical intervention is reserved for actual or impending rupture, malperfusion, or intractable pain). ${ }^{2,3}$ They point out rightly that neither the Acute Dissection: Stent Graft or Best Medical Therapy (ADSORB) trial ${ }^{4}$ nor the LongTerm Results of the Randomized Investigation of Stent Grafts in Aortic Dissection (INSTEAD-XL) trial ${ }^{5}$ provided unequivocal evidence of benefit from routine endovascular stenting. ADSORB, the authors point out, "showed no benefit of TEVAR [thoracic endovascular aortic repair] in terms of mortality, prevention of aortic rupture, or dilatation." INSTEAD-XL, they point out, found a higher 2year mortality in the thoracic endovascular aortic repair group than in the best medical therapy group $(6.9 \%$ vs $2.9 \%$, respectively).

Sensing this equipoise, Matsushita and colleagues ${ }^{1}$ took a very rational approach: Maybe, they posited, there will not be a single optimal strategy for all patients with uncomplicated type B aortic dissection. In other words, maybe this is not a "one size fits all" situation. Maybe, they reasoned, we should look for early markers to identify those patients with uncomplicated type B aortic dissection who will not do well with medical management alone and select them out for endovascular or open surgical therapy.

Matsushita and colleagues ${ }^{1}$ took a steady aim at this question. They produced a study with a large number of patients followed up for a long period. Furthermore, they true lumen; and

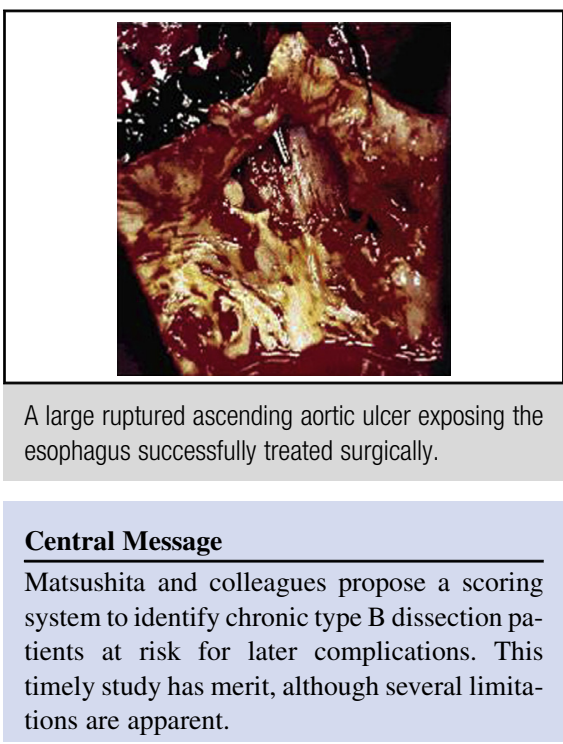

See Article page 2173.

confirmed their findings in a large replication group from other hospitals. Finally, they applied advanced statistical methods. In doing so, they produced a rubric that tells us that patients with the following parameters are at increased risk of "late aortic events":

- Those with an initial aortic diameter larger than $4 \mathrm{~cm}$;

- Those with a false lumen larger than the true lumen;

- Those with an "ulcerlike projection" (ULP) from the

- Those older than 70 years.

They admirably developed a simple point system that was based on these criteria. Our concerns are the following:

\section{Inclusion of Patients With Intramural Hematoma in Patient Group}

One issue that we see with this work is the inclusion by Matsushita and colleagues ${ }^{1}$ of patients with intramural hematoma (IMH) in the type B group, claiming that they are difficult to distinguish. Although some cases may be equivocal, however, IMHs are generally circumferential (no flap), whereas true dissections have a flap. ${ }^{3}$ In most cases, this distinction is simple and immediately apparent. Taking this line of analysis a step further, it is unclear to us how a typical dissection can have a ULP. (Indeed, their illustrations of "ULPs" in their graphical abstract seem to be in IMH aortas.) Where would a ULP protrude in a typical 


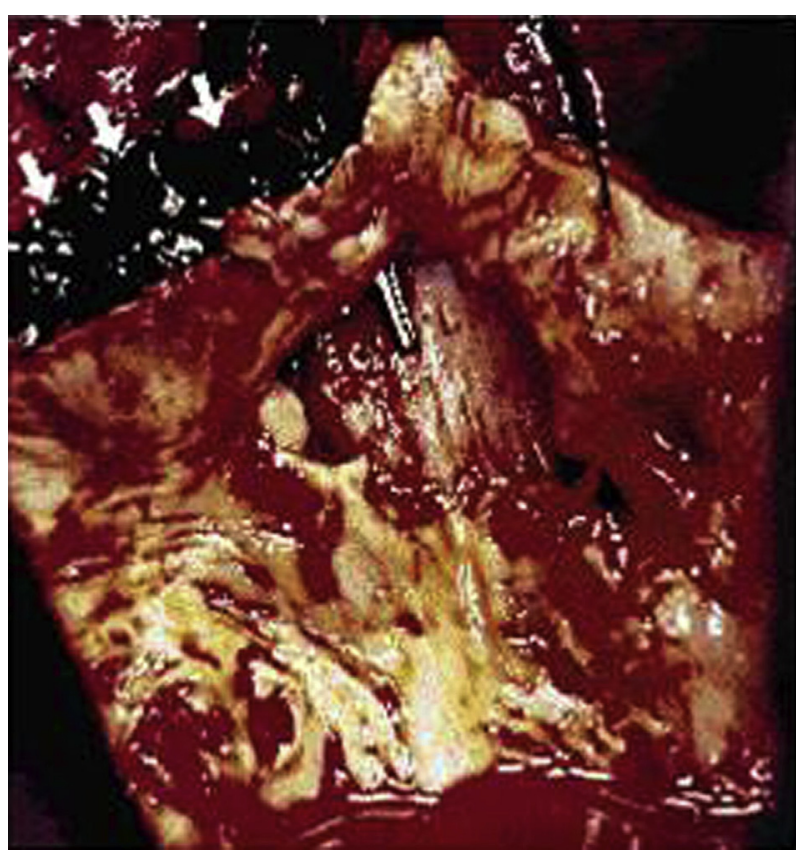

FIGURE 1. A large ruptured ascending aortic ulcer exposing the esophagus successfully treated surgically.

dissection? Into the false lumen? Then it would be a simple fenestration (please see Figure 1 for a dramatic aortic ulcer). This point becomes important, because Matsushita and colleagues ${ }^{1}$ have rendered ULP a criterion for intervention. They may be skewing their results regarding typical "flap type" aortic dissections by this inclusion of patients with IMH in the patient group.

\section{"Soft" End Points}

An even more central issue is the following. Matsushita and colleagues ${ }^{1}$ state that they are predicting "aortic events." This makes us think of hard events, specifically, rupture and death. Matsushita and colleagues, ${ }^{1}$ however, consider aortic enlargement to $5.5 \mathrm{~cm}$ or growth more than $1 \mathrm{~cm} / \mathrm{y}$ to be "aortic events" in their analysis. They are thus using an initial size criterion to predict a later size event - a circular reasoning pattern, in a way. If they were predicting only hard events, such as rupture and death, we would be more comfortable. Also, growth at $1 \mathrm{~cm} /$ year is very uncommon in our experience with thousands of patients at the Aortic Institute at Yale University. Such an observation is usually found to be spurious on close analysis, reflecting measurement error resulting from obliquity of the aortic arch or comparison of noncorresponding segments. Furthermore, concern mounts when we observe that the "soft" outcomes of meeting a size or ULP or growth criterion constituted the "aortic event" in 48 of 49 of their "event" patients.

\section{Cause of Death}

We were surprised that Matsushita and colleagues ${ }^{1}$ were able to classify all deaths as conclusively "aortic" or "nonaortic." We have trouble doing this. We establish an intermediate category, following the lead of Lederle and associates $^{6}$ from their abdominal aortic aneurysm rupture study. We consider sudden death without imaging, surgical, or autopsy proof of aortic origin as "possible aortic death."

\section{Inclusion of Surgical Intervention as an "Event"}

We usually dislike inclusion of a surgical event as an end point in development of algorithms predictive of disease behavior, because this is reflective of a surgeon's decision, rather than the behavior of the native disease. In this case, however, Matsushita and colleagues ${ }^{1}$ state clearly that they operated only for aortic dimension greater than $5.5 \mathrm{~cm}$. If this is so, why do they need to use both the surgical event and the dimension as event indicators? Are they not "double counting"?

\section{CONCLUSIONS}

In summary, we commend Matsushita and colleagues ${ }^{1}$ on their effort to tackle this clinically important problem. Addressing some of the study limitations and validating the results at other high-volume centers will shed light on the true validity of the proposed risk score.

\section{References}

1. Matsushita A, Tabata M, Mihara W, Shimamoto T, Komiya T, Takanashi S, et al Risk score system for late aortic events in patients with uncomplicated type B aortic dissection. J Thorac Cardiovasc Surg. 2020;159:2173-83.e1.

2. Elefteriades JA, Hartleroad J, Gusberg RJ, Salazar AM, Black HR, Kopf GS, et al. Long-term experience with descending aortic dissection: the complicationspecific approach. Ann Thorac Surg. 1992;53:11-20; discussion 20-1.

3. Charilaou P, Ziganshin BA, Peterss S, Rajbanshi BG, Rajakaruna C, Zaza KJ, et al. Current experience with acute type B aortic dissection: validity of the complication- specific approach in the present era. Ann Thorac Surg. 2016;101:936-43.

4. Brunkwall J, Kasprzak P, Verhoeven E, Heijmen R, Taylor P; ADSORB Trialists, et al. Endovascular repair of acute uncomplicated aortic type B dissection promotes aortic remodelling: 1 year results of the ADSORB trial. Eur J Vasc Endovasc Surg. 2014;48:285-91.

5. Neinaber CA, Kische S, Rousseau H, Eggebrecht H, Rehders TC, Kundt G, et al; INSTEAD-XL trial. Endovascular repair of type B aortic dissection: long-term results of the randomized investigation of stent grafts in aortic dissection trial. Circ Cardiovasc Interv. 2013;6:407-16.

6. Lederle FA, Johnson GR, Wilson SE, Ballard DJ, Jordan WD Jr, Blebea J, et al; Veterans Affairs Cooperative Study \#417 Investigators. Rupture rate of large abdominal aortic aneurysms in patients refusing or unfit for elective repair. JAMA. 2002;287:2968-72. 